\title{
The Impact of Writing Practices on Students' Mathematical Attainment
}

\author{
Ali Bicer ${ }^{1 *}$, Celal Perihan ${ }^{2}$, Yujin Lee ${ }^{3}$ \\ ${ }^{1}$ University of Wyoming, USA \\ 2 Idaho State University, USA \\ ${ }^{3}$ Texas A\&M University, USA \\ *CORRESPONDENCE: $\square$ abicer@uwyo.edu
}

\begin{abstract}
The purpose of this meta-analysis was to examine the effects of writing intervention on students' mathematical attainment based on their achievement (mathematics standardized test scores) and their attitudes toward mathematics (mathematical motivation and interest). Twelve studies with 19 effect sizes were selected for inclusion in the present meta-analysis. Results indicated that the overall effect size equalled 0.42 . The small sample size (12 studies) in the present meta-analysis limits the generalizations that might be made regarding the overall impact of writing intervention on students' mathematical attainment. However, the implication from the present study is that integrating writing into mathematics classrooms can be a useful instructional strategy to increase students' mathematics success.
\end{abstract}

Keywords: integrating writing into mathematics, writing in mathematics, mathematical writing, mathematical attainment

\section{INTRODUCTION}

The National Council of Teachers of Mathematics (NCTM) emphasized the importance of communication by placing communication in two of its calls for proposals in 1989 and 2000 . The council, through these two calls, conveyed the idea that communication is an integrated part of mathematics classrooms and that it is crucial for students to be able to communicate their mathematical ideas to clarify and develop their mathematical thinking and understanding (NCTM 1989, 2000). Through language, students in mathematics classrooms convey their thoughts to others and construct a model of their mathematical thinking (Sierpinska 1998). Neria and Amit (2004) conducted a study to determine students' mathematical communication preferences. They found that only high achieving students preferred to use the algebraic communication mode when representing their mathematical solutions. Cai et al. (1996) also reported that students preferred to represent their mathematical solutions verbally rather than in algebraic or geometric form. NCTM (2000) reported that all school-aged students in mathematics classrooms should not only be able to communicate by using algebraic and geometric modes of mathematical communication, but also be able to share their mathematical reasoning with others. Later, Nathan and Koedinger (2000) revealed that students preferred to explain their reasoning in non-algebraic modes because algebraic modes were too abstract, and the abstract quality of algebraic modes made mathematical communication difficult for the students (Hembree 1992). To enable not only high achieving students but all students to communicate mathematically, writing needs to be integrated into mathematics classrooms.

\footnotetext{
Article History: Received 26 July 2018 • Revised 10 August 2018 Accepted 26 September 2018

(C) 2018 The Author(s). Open Access terms of the Creative Commons Attribution 4.0 International License (http://creativecommons.org/licenses/by/4.0/) apply. The license permits unrestricted use, distribution, and reproduction in any medium, on the condition that users give exact credit to the original author(s) and the source, provide a link to the Creative Commons license, and indicate if they made any changes.
} 
Integrating writing into mathematics classrooms has recently received increased attention (Meiner \& Rishel 1998). Seto and Meel (2006) highlighted the importance of writing by emphasizing one of the crucial changes over recent decades in mathematics teaching and learning: writing has been integrated into an increasing number of mathematics classrooms as a communication tool (Bicer, Capraro, \& Capraro 2013). Incorporating written communication in mathematics classrooms is important because it provides students with a tool to reflect their mathematical reasoning and involves the mathematical community (Fried \& Amit 2003; Morgan 1994). Therefore, writing needs specific attention in mathematics classrooms to increase students' communication and make their mathematics learning meaningful by requiring them to actively use mathematical vocabulary, phrases, shapes, and meanings (Thompson \& Rubenstein 2000) in real-life contexts.

\section{Using Writing as a Tool in Mathematics}

Writing has received growing attention in mathematics classrooms because it helps develop students' mathematical content learning (Meel, 1999) and problem-solving skills (Bagley \& Gallenberger, 1992). Integrating writing into mathematics classrooms improves students' problem-solving skills because it requires students to reflect on their mathematical thinking during the problem-solution process (Bangert-Drowns, Hurley, \& Wilkinson 2004). Through writing, students collect, scrutinize, and interpret various problemsolution processes, thus enabling them to externalize internal mathematical reasoning for direct interpretation (Nahrgang \& Petersen 1986). Duke and Pearson (2002) and Haneda and Wells (2000) found that students in mathematics classrooms with writing intervention had deeper mathematical comprehension than students in mathematics classroom without writing, and Kreeft (1984) found that students' metacognition developed as they became aware of and controlled their mathematical ideas and understanding through writing.

Writing in mathematics classrooms is helpful practice because it provides students an opportunity to represent their processes of mathematical reasoning, such as analysing data, comparing and contrasting mathematical problems, and synthesizing relevant mathematical information (Emig, 1977). Bicer et al. (2013) noted that mathematical questions are occasionally complex or troublesome for some students to solve because they may have difficulties organizing their thoughts using algebraic or geometric language. However, writing can assist these students in organizing their mathematical thinking process to attain mathematical products or outcomes; as a result, writing helps them become successful problem solvers, even when they face mathematical questions that require a complex solution process. "Thus, the writing process may encourage students to solve difficult problems because writing makes difficult problems more concrete rather than an abstract or imaginary thing" (Bicer et al., 2013, 366). Because writing requires students to represent their mathematical reasoning, their mathematical thinking becomes more concrete, original, and insightful (Nagin, 2003).

The benefits for students who are exposed to writing in mathematics classrooms are well-documented; to summarize, writing in mathematics classrooms fosters students' reasoning skills (Swafford and Bryan 2000) by converting more complex mathematical questions into concrete ones and develops their metacognition (Kreeft, 1984; Stanton, 1984) by providing opportunities for them to see what and how they know mathematical terms, axioms, or theorems (Bicer et al., 2013). Although researchers have acknowledged the importance of writing in mathematics and have examined the impact of writing intervention on student learning (Bangert-Drowns et al., 2004; Bicer et al., 2003; Nagin, 2003; NCTM, 2000), researchers have yet to conduct meta-analyses in which they focus solely on the effects of writing intervention on students' mathematical attainment. Thus, the aim of this meta-analysis was to examine the impact of writing practices on students' mathematical attainment based on their achievement (mathematics standardized test scores) and their attitudes towards mathematics (mathematical motivation and interest).

\section{METHODS}

\section{Study Identification}

\section{Literature search}

The primary research question of the present study was the following: How does writing intervention affect students' mathematical attainment? To address our research question the researchers applied a meta-analytic technique. Meta-analysis is a useful tool in compiling crucial insight from what might otherwise be a disparate literature (Bangert-Drowns, Hurley, \& Barbara 2004). The electronic databases of ERIC, JSTOR, CrossRef, 


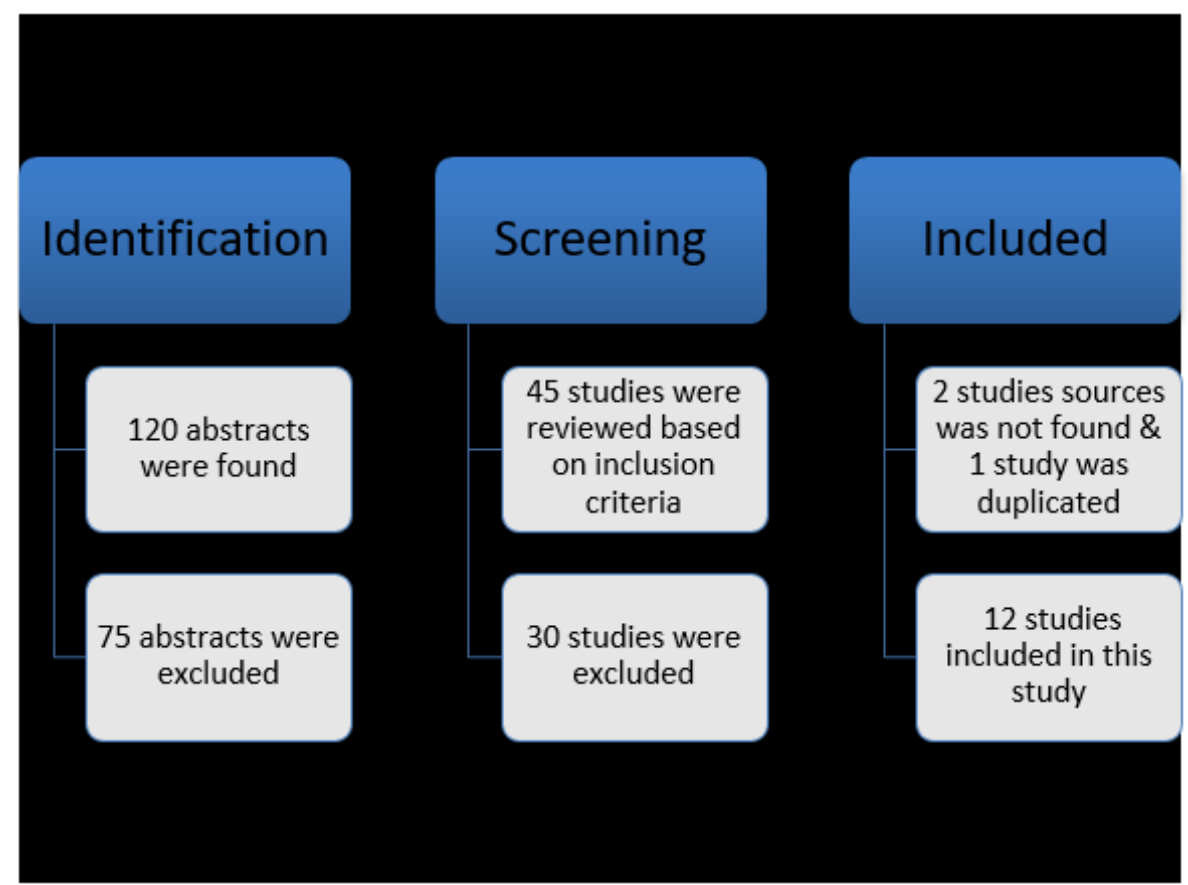

Figure 1. Selection of the studies in the meta-analysis of The Effects of Writing Intervention on Students' Mathematics Success

pyschINFO, proQest, as well as online resources, such as Google and Google Scholar were searched to compile data for the present study. The researchers searched for relevant studies using the following keywords: "writing in mathematics", "writing in mathematics classrooms", "integrating writing into mathematics", "writing to learn mathematics", "writing and students' attitudes towards mathematics", "mathematical writing", and "writing and mathematics". The abstract of each study was reviewed, and the studies were accepted based on the following inclusion and exclusion criteria.

\section{Inclusion and exclusion criteria}

Experimental and/or quasi-experimental studies that met the following inclusion criteria were included in the present meta-analysis: (1) published in English; (2) measured students' mathematics achievement and mathematics attitudes; (3) involved students in grades K-12 and college; (3) published in 1989 or later, as NCTM (1989) emphasized the importance of writing in mathematics classrooms; (4) included examinations of students' academic performance in algebra, geometry, or calculus as measured by a standardized test score or; (5) included examinations of students' attitudes towards mathematics, including mathematical motivation and interests; (6) included use of journal writing or exploratory writing as an intervention in mathematics classrooms; (7) and published in peer-reviewed journals. The researchers also performed a backwards search using the studies cited in other articles to locate additional sources. After finding too few articles when they focused solely on students' mathematics achievement, it was necessary for the researchers to broaden their scope of analysis to include studies in which students' attitudes toward mathematics were examined. Therefore, in the current study, the researchers defined students' mathematical attainment with measures of mathematics achievement and attitudes. Upon completion of the entire search process, they had located 12 quantitative and mixed method studies that examined the impact of writing intervention on students' mathematics success.

Studies that lacked any of the inclusion criteria were excluded from the present meta-analysis. A large number of studies were excluded from this meta-analysis because they focused on the impact of writing in subjects other than mathematics. Studies that focused on teachers or classroom effectiveness were also excluded from the present meta-analysis. See Figure 1 for a flowchart diagram for selection of the studies.

\section{Extraction of Descriptive Information and Inter-rater Agreement}

Each study was coded independently by the researchers using coding sheets to document the following information: author name, sample size, grade, feedback, length of writing intervention, types of writing 
intervention, and place of writing intervention. After initial coding of the studies by the first and second authors, another researcher evaluated any points of disagreement, and studies were included in the current meta-analysis once the disagreements were resolved. The inter-rater agreement related to determining the continuous variables was 0.95 , which was an excellent agreement.

\section{Analysis \\ Effect sizes}

Standard mean differences were used to compute Cohen's $d$ effect sizes from means, standard deviations, and sample sizes. The effect size for each study was calculated based on students' pre- and post-test scores for mathematics achievement and attitudes. If there was more than one effect size within a single study, the effect sizes were combined and averaged. For example, if one study included an effect size for middle school female students' geometry scores and an additional effect size for their algebra scores, the two effect sizes would have been combined and averaged to determine their overall mathematics achievement; in this instance, there would be a single, averaged effect size. However, when a study contained effect sizes for different groups, such as one effect size for female students and one effect size for male students, we reported or calculated each effect size as an individual study. To correct for sampling bias, all effect sizes were converted to Hedges's $g$ effect size, and the 95\% confidence interval was then calculated (Cohen, 1988). Wilson's ES calculators, based on formulas provided by Lipsey and Wilson, were used to convert Cohen's $d$ to Hedges's $g$ (Lipsey \& Wilson 2001). A weighting procedure was applied to each study's effect size based on its sample size to produce a weighted Hedges's $g$, and the associated standard error for the effect size was also computed. Using the effect sizes from all of the studies, the researchers were able to calculate an overall mean effect size and standard error (Cooper, 2010; Lipsey \& Wilson, 2001) for the present meta-analysis.

\section{Random-effects Model and Moderator Analyses}

\section{Random-effects model}

Because the studies' characteristics functionally differed, a random-effects model was used. Therefore, it was expected that the true effect size would be different. Selecting a random-effects model was also desirable in the present study, as the goal was to compute the common effect size to generalize the results to other populations. The random-effects model allowed the researchers to generate generalized results that were not found in the studies included in the current meta-analysis. In order to determine substantial outliers, we constructed a funnel plot. The funnel plot was arranged as a $95 \%$ confidence interval around each of the effect sizes.

\section{Moderator analyses}

During the analysis of the articles, several potential moderators related to the studies were also examined. After reading the selected studies, the researchers found four potential variables functioning as moderators within the studies: (1) the division of students into two groups based on whether they received feedback or not; (2) the place students performed writing, divided into two groups: classroom and classroom and home; (3) types of writing students performed in mathematics classrooms, divided into two groups: exploratory writing and journal writing; (4) grades levels, divided into two groups as K-12 and college. As an indicator of homogeneity, Cochran's heterogeneity Q-statistic was used. Based on statistically significant results of Cochran's heterogeneity Q-statistic for overall studies, possible moderators were categorized and analysed between and within the subgroups. Forest plots were also used to illustrate the relative strength of intervention with their $95 \%$ confidence interval (CI).

\section{FINDINGS}

\section{Participant Characteristics}

A total of 120 studies were identified during our electronic search. After reviewing titles and abstracts based on the inclusion and exclusion criteria, and removing duplicates, 12 studies with 19 effects sizes were included in this current meta-analysis. This meta-analysis contained more effect sizes than the number of studies it included because some of the included studies reported different effect sizes for different groups. In such studies, effect sizes of different groups were reported for the same construct; in the current study, each of these instances was calculated and reported as one effect size. Table 1 displays each study's sample size, 
Table 1. Forest plot of studies included in the meta-analysis

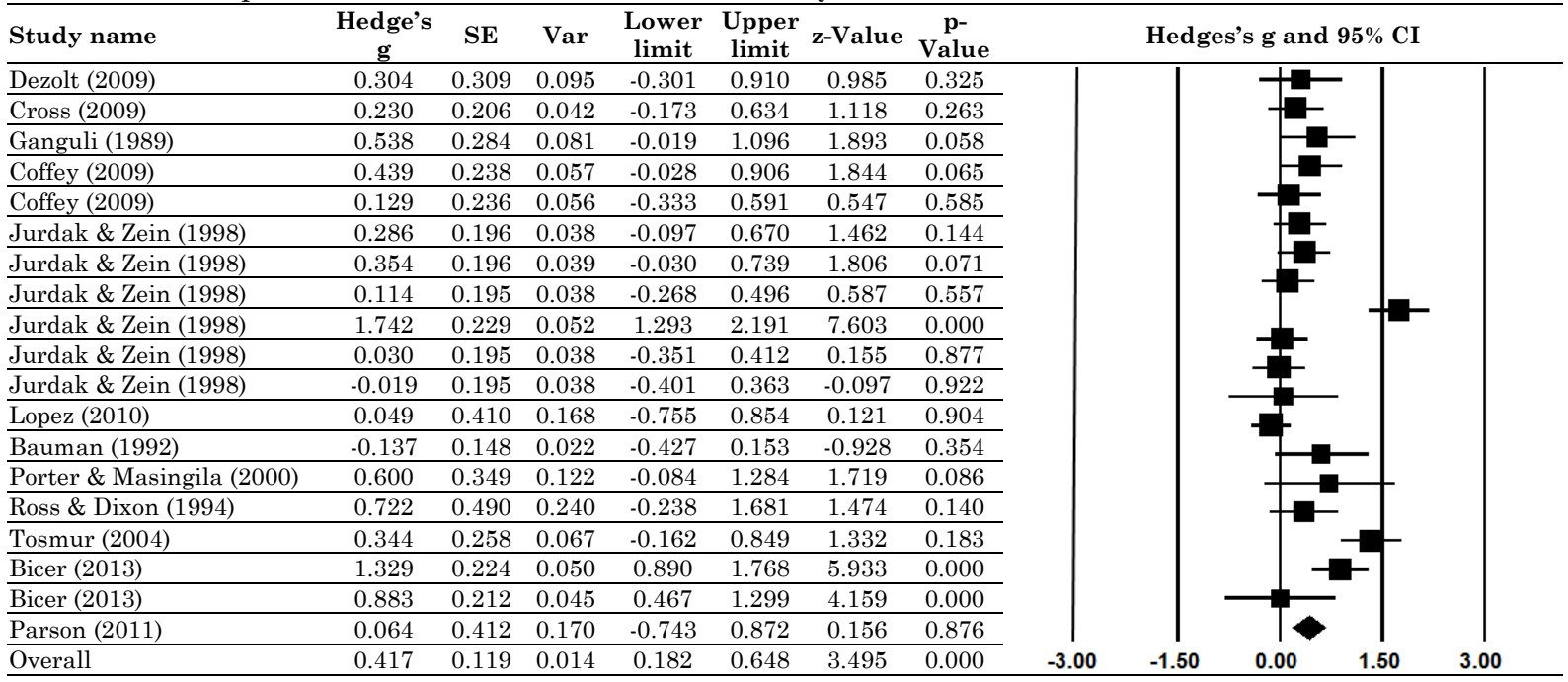

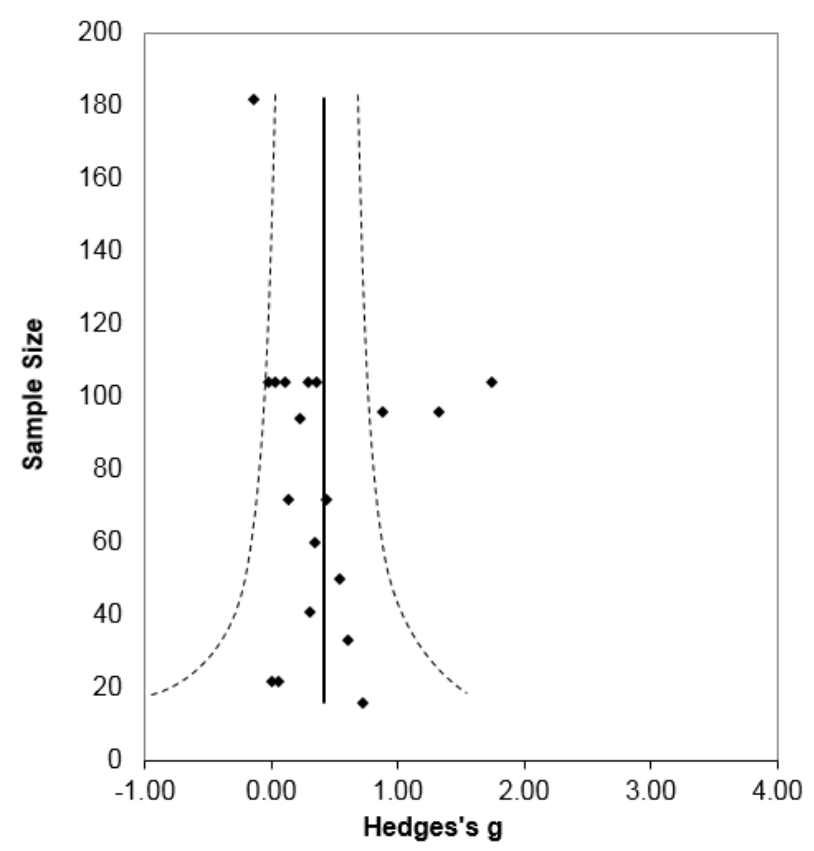

Figure 2. Funnel plot of included studies

grade, feedback, length of writing intervention, types of writing intervention, and place of writing intervention. All studies were randomized controlled trials comparing to a waitlist. These studies' sample sizes varied. The studies with the smallest sample sizes were Parson (2011) with $(n=22)$ participants and Ross and Dixon (1994) with $n=16$. The study with the largest sample size was Buaman (1994) with $n=182$. Overall, the total sample size was 1480 .

The age of participants varied from 10 to 24 .

\section{Treatment Efficacy}

Results of a random-effects model on the current study showed quite a range in effect size values. The results extended from a low value of -0.137 to a high of 1.74 . Within this range, only two effect sizes were negative. The overall mean of the weighted effect sizes was statistically significant $(g=0.42,95 \%$ CI 0.18 , $0.65, \mathrm{z}=3.50, \mathrm{p}<.05)$ with significant heterogeneity $[\mathrm{Q}(18)=83.85, \mathrm{p}<.05]$. Table 1 displays each study's Hedges's $g$, sample size, $95 \%$ CI, variances, $p$-values, $z$-values, weighted effect size, and standard errors. See Figure 2 for treatment effect sizes. 


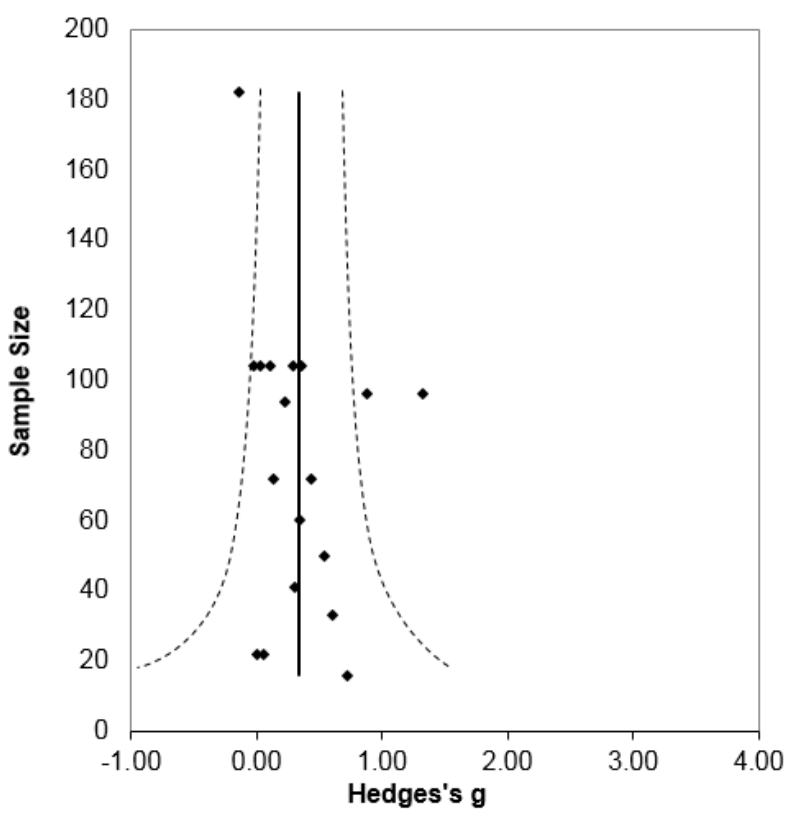

Figure 3. Funnel plot of included studies without outlier

Funnel plots were used for causal inspection. The funnel plot in Figure 2 shows four outliers among the 19 effect sizes in the present study: 1) Bauman (1992), 2) Jurdak and Zein (1998), 3) Bicer, Capraro, and Capraro (2013), and 4) Bicer et al. (2013). Several of these outliers, Bauman (1992), Bicer et al. (2013), and Bicer et al. (2013), were close to the upper and lower boundary of the confidence interval. However, Jurdak and Zein (1998) was a substantial outlier for the construct of mathematical communication and representation; this outlier can be seen in the middle right side of Figure 2. In addition, among these four outliers, only Bauman (1992) had a negative effect size (Hedges's $g=-0.14$ ) and a relatively large sample size $(\mathrm{N}=182)$ for the construct of mathematics achievement. Based on the results of the funnel plot, only Jurdak and Zein (1998) was determined a substantial outlier. Removing the study reduces the overall effect size, but the effect size was still statistically significant $(g=0.33,95 \%$ CI 0.15, 0.52, z $=3.54, p<.05$ ). See Figure 3 for the funnel plots.

\section{Moderator Analysis}

\section{The effects of feedback}

The first moderator was used to determine whether or not there were any differences in effect sizes between studies in which students received feedback and those in which they did not. Effect sizes did not significantly differ between instances in which feedback was and was not provided: feedback $(g=0.40 \%$ CI $0.16,0.64, \mathrm{z}=$ $3.22, \mathrm{p}<.05$ ), no feedback ( $g=0.44,95 \%$ CI $0.10,0.79, \mathrm{z}=2.49, \mathrm{p}<.05$ ). Removing the outlier did not cause significant changes in the results. Results of Q-statistics demonstrated that the Q-between was not statistically significant $\left[\mathrm{Q}_{\text {в }}(1)=0.04, \mathrm{p}>.05\right]$, meaning that the moderator variables (i.e., receiving feedback and not receiving feedback) did not explain differences between the effect sizes. Furthermore, the $\mathrm{Q}$-within was statistically significant $\left[\mathrm{Qw}_{\mathrm{w}}(15)=82.26, \mathrm{p}<.05\right]$, indicating that the variation among the effect sizes was not due to sampling error, and there were no significant differences within the studies.

Researchers used the second moderator analysis to examine any differences in effect sizes based on where each writing assignment was completed (i.e., classroom or both classroom and home). In terms of location, effect sizes significantly differed between classroom intervention and classroom and home intervention; the results were $(\mathrm{g}=0.29 \% \mathrm{CI} 0.01,0.59, \mathrm{z}=0.9, \mathrm{p}>.05)$ for classroom intervention and $(\mathrm{g}=0.70,95 \%$ CI 0.40 , $1.01, \mathrm{z}=4.54, \mathrm{p}<.05)$ for classroom and home intervention. Removing the outlier did not cause a significant difference in these effect sizes, and after its removal, there were still statistically significant differences between the intervention locations. Q-statistics also demonstrated the significant differences between the groups $[\mathrm{QB}(1)=16.89, \mathrm{p}<.05]$. Q-statistics within the groups were also statistically significant $[\mathrm{QW}(16)=$ $65.81, \mathrm{p}<.05]$, which suggested that writing location could explain differences between studies' effect sizes and indicated that effect-size variation was not due to sampling error. 
The third moderator analysis was used to analyse whether or not there were any differences in effect sizes between journal writing intervention and exploratory writing intervention. There was a statistically significant difference in effect sizes between journal writing intervention and exploratory writing intervention; the results were $(g=0.26 \%$ CI $0.14,0.93, \mathrm{z}=4.05, \mathrm{p}<.05)$ for journal writing intervention and $(g=0.58,95 \%$ CI $0.25,0.92, \mathrm{z}=3.40, \mathrm{p}<.05)$ for exploratory writing intervention. Removing the outliner did not cause statistically significant changes in effects sizes across types of writing. Differences between journal writing intervention and exploratory writing intervention were also found statistically significant with Q-Statistics [Qв $(1)=9.70, \mathrm{p}<.05]$, which suggested that effect-size variation was not due to sampling error. Studies within the groups had homogeneity $\left[\mathrm{Qw}_{\mathrm{w}}(16)=73.00, \mathrm{p}<.05\right]$, which suggested that types of writing in mathematics could explain differences between studies' effect sizes.

The fourth and last moderator analysis was used to examine any differences in effect sizes based on grade levels K-12 and those after K-12 (college). Effect sizes significantly differed between K-12 and post-secondary education (college); K-12 results were $(g=0.48 \%$ CI $0.18,0.79, \mathrm{z}=3.09, \mathrm{p}<.05)$ and college results were $(g=$ $0.24,95 \%$ CI $-0.04,0.52, \mathrm{z}=1.68, \mathrm{p}>.05)$. Removing the outlier did not cause statistically significant changes in effects sizes across grade levels. This analysis produced statistically significant differences between and within grade levels $\left[\mathrm{Q}_{\mathrm{B}}(1)=7.33, \mathrm{p}<.05 ; \mathrm{Qw}(18)=75.07, \mathrm{p}<.05\right]$.

\section{DISCUSSION AND CONCLUSIONS}

The ultimate research question the researchers sought to answer through this meta-analysis was the following: What impact does writing intervention have on students' mathematical attainment? The results of the study indicated that writing intervention has a significantly positive effect on students' mathematical attainment: the overall effect size was 0.42 , and the average of the weighted mean effect sizes was 0.367 with $S D=0.053$. As cited in Cooper (2010) and Lipsey and Wilson (2001), Cohen identified any effect size between 0.20 and 0.80 as a medium effect size. Therefore, the weighted mean effect size computed here reflects a medium effect of writing intervention on students' mathematical attainment. However, many of the studies were excluded from this analysis because they did not report the appropriate statistics. Cooper (2010) noted that other analyses might not have been published due to non-significant results. Additionally, the current study presents only 12 studies about the effects of writing intervention on students' success; thus, any results of this meta-analysis need to be considered cautiously. These limitations restrict the overall impact of writing intervention on students' mathematics achievement to which the results of the present meta-analysis can be generalized.

Three of the four moderator analyses conducted in this meta-analysis helped to clarify the reasons for the variation in effect sizes. These three moderator analyses were the following: 1) the location where the writing intervention occurred, 2) the types of writing intervention, and 3) the grade level. However, the other moderator analysis, "receiving feedback or receiving no feedback," did not help to clarify the reasons for the variation in effect sizes. The Q-tests (within in all four moderators) also made clear that assuming a randomeffects model for these moderator analyses is appropriate because the variation in the effect sizes cannot be explained solely by sampling error.

In light of the present study's findings, it is important that teachers who want to integrate writing into their classroom consider the moderators or factors that influence the differential effects on students' mathematical attainment. Teachers should enable students to engage with mathematical writing in both classroom and home settings to help students acquire the potential benefits of writing intervention on their mathematical attainment. It is also important to point out that integrating writing in mathematics classrooms is more beneficial during K-12 years than it is in college; college students can be more aware of their mathematical weaknesses, misconceptions, and misbeliefs than K-12 students. Writing intervention can increase K-12 students' metacognition by helping them become aware of what their own mathematical strengths and weakness are. This difference can also be explained by the other finding of the present study: students who participated in exploratory writing intervention showed greater mathematical attainment than their counterparts who received journal writing intervention. During exploratory writing intervention, students explore new mathematical ideas and have a chance to connect these ideas to their previous mathematical knowledge. This makes students' mathematical understanding more meaningful, and this might be the reason why exploratory writing intervention is more helpful for students to understand mathematics content than journal writing intervention. Therefore, teachers should incorporate more exploratory writing within mathematics classrooms. If the sphere of literature in this meta-analysis were 
broadened, its results would be more reliable and helpful to mathematics teachers in key decisions regarding the teaching and learning of mathematics.

\section{Disclosure statement}

No potential conflict of interest was reported by the authors.

\section{Notes on contributors}

Ali Bicer - University of Wyoming, USA.

Celal Perihan - Idaho State University, USA.

Yujin Lee - Texas A\&M University, USA.

\section{REFERENCES}

Bagley, T., \& Gallenberger, C. (1992). Assessing Students' Dispositions: Using Journal to Improve Students' Performance. Mathematics Teacher, 85(8), 660-663. http://www.jstor.org/stable/27967836

Bangert-Drowns, R. L., Hurley, M. M., \& Wilkinson, B. (2004). The Effects of School Based Interventions on Academic Achievement: A Meta-Analysis. Review of Educational Research, 74(1), 29-58. https://doi.org/10.3102\%2F00346543074001029

Bauman, M. A. (1992). The effect of teacher-directed journal writing on fifth-grade student mathematics achievement. Dissertation Abstracts International, 53(6), 1830A. UMI No. 9227116.

Bettencourt, C. (2009). Promoting Social Change through Writing: A Quantitative Study of Research-Based Best Practices in Eighth-Grade Mathematics. PhD diss. Walden University, TN. Proquest Dissertations Publishing (3379789).

Bicer, A., Capraro, R. M., \& Capraro, M. M. (2013). Integrating Writing into Mathematics Classroom to Increase Students' Problem Solving Skill. International Online Journal of Educational Sciences, 5(2), 361-369. Retrieved from http://www.iojes.net/userfiles/Article/IOJES_1118.pdf

Cai, J., Magone, M. E., Wang, N., \& Lane S. (1996). A Cognitive Analysis of QUASAR's Mathematics Performance Assessment Tasks and Their Sensitivity to Measuring Changes in Middle School Students' Thinking and Reasoning. Research in Middle Level Education Quarterly, 19(3), 65-96. https://doi.org/10.1080/10848959.1996.11670075

Coffey, H. (2009). The Relationship between Metacognition and Writing in Sixth Grade Mathematics. PhD diss. Dissertation Abstract International (UMI No. 3379789).

Cooper, H. (2010). Research Synthesis and Meta-Analysis: A Step-by-Step Approach. $4^{\text {th }}$ ed. Thousand Oaks, CA: Sage.

Cross, D. I. (2009). Creating Optimal Mathematics Learning Environments: Combining Argumentation and Writing to Enhance Achievement. International Journal of Science and Mathematics, 7, 905-930. https://doi.org/10.1007/s10763-008-9144-9

Emig, J. (1977). Writing as a Mode of Learning. College Composition and Communication, 28(2), 122-28. https://doi.org/10.2307/356095

Fried, M. N., \& Amit, M. (2003). Some Reflections on Mathematical Classroom Notebooks and their Relationship to the Public and Private Nature of Students Practices. Educational Studies in Mathematic, 53(July), 91-112. https://doi.org/10.1023/A:1025572900956

Ganguli, A. B. (1989). Integrating Writing in Developmental Mathematics. College Teaching, 37(4), 140-142. http://www.jstor.org/stable/27558364

Haneda, M., \& Wells, G. (2000). Writing in Knowledge-Building Communities. Research in the Teaching of English, 34, 430-453.

Hembree, R. (1992). Experiments and Relational Studies in Problem Solving: A Meta-Analysis. Journal for Research in Mathematics Education, 23(3), 242-273. https://doi.org/10.2307/749120

Jurdak, M., \& Abu Zein, R. (1998). The Effect of Journal Writing on Achievement in and Attitudes toward Mathematics. School Science and Mathematics, 98(8), 412-419. Retrieved from https://search.proquest.com/docview/195204294?accountid=7082 
Kreeft, J. (1984). Dialogue Journal Writing: Bridge from Talk to Essay Writing. Language Arts, 61(2), 141150. http://www.jstor.org/stable/41405149

Lipsey, M. W., \& Wilson, D. B. (2001). Practical Meta-Analysis. Thousand Oaks, CA: Sage.

Lopez, S. C. (2010). Towards Evidence-Based Practices in Mathematics Instruction: Investigating the Impact of Writing on Students Ability to Solve Mathematics Problems (PhD diss.), Loyola University Chicago. Retrieved from http://ecommons.luc.edLu/luc_diss/121

Meel, D. (1999). Email Dialogue Journals in a College Calculus Classroom: A Look at the Implementation and Benefits. Journal of Computers in Mathematics and Science Teaching, 18(4), 387-413.

Meiner, J., \& Rishel, J. (1998). Writing in the Teaching and Learning of Mathematics. Washington, DC: The Mathematical Association of America.

Morgan, C. (1994). Writing Mathematically. Mathematics Teaching, 146, 18-21.

Nahrgang, C. L., \& Peterson, B. T. (1986). Using Writing to Learn Mathematics. Mathematics Reacher, 79, 461-465.

Nathan, M. J., \& Koedinger, K. R. (2000). Teachers and Researchers' Beliefs about the Development of Algebraic Reasoning. Journal for Research in Mathematics Education, 31(2), 168-190. https://doi.org/10.2307/749750

National Council of Teachers of Mathematics. (1989). Curriculum and Evaluation Standards for School Mathematics. Reston, VA: National Council of Teachers of Mathematics.

National Council of Teachers of Mathematics. (2000). Principles and Standards for School Mathematics. Reston, VA: National Council of Teachers of Mathematics.

National Writing Project, \& Nagin, C. (2003). Because Writing Matters: Improving Student Writing in our Schools. San Francisco, CA: Jossey-Bass.

Neria, D., \& Amit, M. (2004). Students Preference of Non-Algebraic Representations in Mathematical Communication. Proceedings of the $28^{\text {th }}$ Conference of the International Group for the Psychology of Mathematics Education, 3, 409-416.

Parson, M. R. (2011). Effect of Writing to Learn in Pre-Calculus Mathematics on Achievement and Affective Outcomes for Students in a Community College Setting: A Mixed Method Approach (Unpublished PhD diss.), Colorado State University, CO.

Porter, M. K., \& Masingila, J. O. (2000). Examining the Effects of Writing on Conceptual and Procedural Knowledge in calculus. Educational Studies in Mathematics, 42(2), 165-177. http://www.jstor.org/stable/3483283

Ross, J., \& Dixon, F. (1994). College Algebra and Writing: A Pilot Project. In Final Report for the Title III.

Sierpinska, A. (1998). Three Epistemologies, Three Views of Classroom Communication: Constructivism, Sociocultural Approaches, Interactionism. In Language and Communication in the Mathematics Classroom, edited by H. Steinberg, M. G. B. Bussi, \& A. Sierpinska, 30-62. Reston, VA: National Council of Teachers of Mathematics.

Stanton, J. (1984). Thinking together: Language interaction in children's reasoning. Urbana, IL: National Council of Teachers of English. (ERIC Document Reproduction Service No. ED 247 607).

Swafford, J., \& Bryan, J. (2000). Instructional Strategies for Promoting Conceptual Change: Supporting Middle School Students. Reading \& Writing Quarterly, 16, 139-161. https://doi.org/10.1080/105735600278006

Thompson, D., \& Rubenstein, R. N. (2000). Learning Mathematics Vocabulary: Potential Pitfalls and Instructional Strategies. Mathematics Teacher, 93(7), 568-574. http://www.jstor.org/stable/27971502

Tosmur, N. (2004). The effects of journal writing on first year engineering students' achievement on integral (Unpublished master's thesis), Middle East Technical University, Turkey. http://citeseerx.ist.psu.edu/viewdoc/download?doi=10.1.1.633.3883\&rep=rep1\&type=pd 